\title{
NMDA Receptors in Retrosplenial Cortex Are Necessary for Retrieval of Recent and Remote Context Fear Memory
}

\author{
Kevin A. Corcoran, Michael D. Donnan, Natalie C. Tronson, Yomayra F. Guzmán, Can Gao, Vladimir Jovasevic, \\ Anita L. Guedea, and Jelena Radulovic \\ Department of Psychiatry and Behavioral Sciences, The Asher Center for the Study and Treatment of Depressive Disorders, Feinberg School of Medicine, \\ Northwestern University, Chicago, Illinois 60611
}

Over time, memory retrieval is thought to transfer from the hippocampus to a distributed network of neocortical sites. Of these sites, the retrosplenial cortex (RSC) is robustly activated during retrieval of remotely acquired, emotionally valenced memories. It is unclear, however, whether RSC is specifically involved in memory storage or retrieval, and which neurotransmitter receptor mechanisms serve its function. We addressed these questions by inhibiting NMDARs in RSC via infusions of APV before tests for context fear in mice. Anterior cingulate cortex (ACC) and dorsal hippocampus (DH), which have been implicated in the retrieval of remote and recent memory, respectively, served as neuroanatomical controls. Surprisingly, infusion of APV only into RSC, but not ACC or DH, abolished retrieval of remote memory, as revealed by lack of freezing to the conditioning context. APV infused into RSC also impaired retrieval of recent memory, but had no effect on conditioning or memory storage. Within-subject experiments confirmed that the role of RSC in memory retrieval is not time limited. RSC-dependent context fear memory retrieval was mediated by NR2A, but not NR2B, subunit-containing NMDARs. Collectively, these data are the first demonstration that NMDARs in RSC are necessary for the retrieval of remote and recent memories of fear-evoking contexts. Dysfunction of RSC may thereby contribute significantly to the reexperiencing of traumatic memories in patients with posttraumatic stress disorder.

\section{Introduction}

Anxiety disorders such as posttraumatic stress disorder (PTSD) are characterized by retrieval of fear-evoking, trauma-related memories that can persist for decades after a traumatic event (Solomon et al., 2009). Although much has been learned about hippocampal mechanisms of memory storage and retrieval, far less is known about the role of cortex in recent memory functions or long after learning has occurred. It is thought that memory retrieval, initially reliant upon hippocampal mechanisms, shifts over time to a distributed network of cortical sites (Squire et al., 2004), but the individual contributions of different cortical regions, and the mechanisms that serve their functions, are not well understood.

In support of a role of the retrosplenial cortex (RSC) in learning, episodic memory, and emotional behavior, human studies have revealed increased RSC activity during retrieval of remote spatial (Rosenbaum et al., 2004) and autobiographical (Steinvorth et al., 2006) memory in healthy subjects, and traumatic memories in PTSD patients (Piefke et al., 2007). Lesion studies in

\footnotetext{
Received April 27, 2011; revised June 18, 2011; accepted June 20, 2011.

Author contributions: K.A.C., N.C.T., and J.R. designed research; K.A.C., M.D.D., N.C.T., Y.G., C.G., and A.G. performed research; K.A.C. analyzed data; K.A.C., N.C.T., Y.G., C.G., V.J., and J.R. wrote the paper.

This work was supported by National Institute of Mental Health Grant MH073669 and Dunbar Funds to J.R. and K12GM088020 to K.A.C.

Correspondence should be addressed to either Kevin A. Corcoran or Jelena Radulovic, Department of Psychiatry and Behavioral Sciences, Feinberg School of Medicine, Northwestern University, 303 East Chicago Avenue, Ward 9-217, Chicago, IL 60611, E-mail: kevincorcoran@gmail.com or j-radulovi@@northwestern.edu.

DOI:10.1523/JNEUROSCI.2107-11.2011

Copyright $\odot 2011$ the authors $\quad 0270-6474 / 11 / 3111655-05 \$ 15.00 / 0$
}

rodents support a role for RSC in memory (Haijima and Ichitani, 2008; Keene and Bucci, 2008a,b; Aggleton, 2010); however, a causal role for RSC in memory retrieval, and the neurotransmitter mechanisms involved, are not known.

In contrast to hippocampal mechanisms of memory retrieval, which predominantly depend on AMPA receptors (AMPARs) (Izquierdo et al., 1997), various cortical regions also rely upon NMDARs (Barros et al., 2000). We therefore tested the effects of NMDAR blockade in RSC on context fear memory retrieval as compared to NMDAR blockade in anterior cingulate cortex (ACC) and dorsal hippocampus (DH), which have been implicated in the retrieval of remotely and recently acquired memories, respectively (Anagnostaras et al., 1999; Frankland et al., 2004). We demonstrated that RSC NMDARs, specifically those containing the NR2A subunit, are necessary for the retrieval of remote and recent memories of fear-evoking contexts, but not for fear conditioning, memory storage, or performance of fear responses.

\section{Materials and Methods}

Subjects. Nine-week-old male C57BL/6N mice obtained from a commercial supplier (Harlan) were used in this study. Mice were individually housed in a facility on a 12/12 h light/dark cycle (lights on at 7 A.M.), and allowed ad libitum access to food and water. All procedures were approved by Northwestern University's Animal Care and Use Committee in compliance with National Institutes of Health standards.

Surgery. Mice were anesthetized with Avertin (1.2\%) and implanted with double 26 gauge guide cannulas (Plastics One) aimed at RSC (1.8 $\mathrm{mm}$ posterior, $\pm 0.4 \mathrm{~mm}$ lateral, $0.75 \mathrm{~mm}$ ventral to bregma), ACC (1.3 $\mathrm{mm}, \pm 0.4 \mathrm{~mm}, 0.75 \mathrm{~mm})$, or DH $(1.5 \mathrm{~mm}, \pm 1.0 \mathrm{~mm}, 2 \mathrm{~mm})$. Mice were 
allowed at least $72 \mathrm{~h}$ to recover from surgery before behavioral procedures.

Infusions. Intracerebral infusions were made using 28 gauge injectors that extended $1 \mathrm{~mm}$ beyond the end of the guide cannulas. NMDAR blockade was achieved via infusion of the NR2 antagonist APV $(10 \mu \mathrm{g} / \mu \mathrm{l}$ in aCSF; Sigma $)$, the NR2A-preferring antagonist NVP-AAM007 (NVP; $1 \mu \mathrm{g} / \mu \mathrm{l}$ in aCSF; Novartis) or the NR2B-specific antagonist RO25-6981 (Ro; 2 $\mu \mathrm{g} / \mu \mathrm{l}$ in $10 \%$ DMSO; Sigma). AMPA receptor blockade was achieved via infusion of CNQX $(0.7 \mu \mathrm{g} / \mu \mathrm{l}$ in $20 \%$ DMSO; Tocris Bioscience). Infusions were made into RSC or ACC at a rate of $0.64 \mu \mathrm{l} / \mathrm{min}$ for $15 \mathrm{~s}$, for a total volume of $0.16 \mu \mathrm{l} /$ side, and into $\mathrm{DH}$ at a rate of $0.8 \mu \mathrm{l} /$ $\min$ for $15 \mathrm{~s}$, for a total volume of $0.2 \mu \mathrm{l} / \mathrm{side}$. All drug and vehicle (Veh) infusions were made 15 min before placing the mice in the conditioning chamber for training or behavioral testing.

Fear conditioning. Fear conditioning took place in context A, a $35 \times 20 \times 20 \mathrm{~cm}$ Plexiglas chamber with a stainless steel rod floor $(4 \mathrm{~mm}$ diameter, $0.9 \mathrm{~cm}$ center to center), in a soundattenuating cabinet with black inner walls (TSE), and was cleaned after each mouse with $70 \%$ ethanol. On day 1 , mice were placed in the chamber and, 3 min later, presented with a tone $(30 \mathrm{~s}, 75 \mathrm{~dB}, 10 \mathrm{kHz}$, pulsed at $5 \mathrm{~Hz})$ followed by a footshock $(2 \mathrm{~s}, 0.7 \mathrm{~mA}$, constant current). Mice were tested for fear to the conditioning context by returning them to this chamber for 3 min tests. Testing for fear to the tone occurred in context $\mathrm{B}$, a novel context comprised of an equally sized, tinted Plexiglas chamber with a solid white plastic floor, situated in a white sound-attenuating cabinet and cleaned with $1 \%$ acetic acid.

Data collection and analysis. Freezing during tests for context fear was scored every $5 \mathrm{~s}$ by a trained observer blind to the experimental conditions, and expressed as the percentage of the total number of observations that the mice remained motionless. Freezing to the tone CS was scored every $3 \mathrm{~s}$. Locomotor activity in the form of infrared beam crosses was collected automatically. Group differences were determined using ANOVA or Student's $t$ tests. Post hoc comparisons were made using Scheffé tests. Mice that froze $<15 \%$ during drug-free tests were not included in the final analyses. Verification of cannula placements was made from coronal sections through RSC, ACC, or DH.

\section{Results}

\section{NMDARs in RSC are necessary for retrieval of remote context} fear memories

We first examined the role of NMDARs in RSC, as compared to DH and ACC, in the retrieval of remotely acquired memory $35 \mathrm{~d}$ after conditioning. The experimental procedure is illustrated in Figure $1 A$. On day 36, infusion of APV into RSC drastically reduced freezing to the conditioning context (Fig. $1 \mathrm{~B}$, right). ANOVA revealed significant main effects of infusion $\left(F_{(1,23)}=6.14, p=0.02\right)$ and test day $\left(F_{(1,23)}=7.94, p=0.01\right)$, and a significant infusion by test day interaction $\left(F_{(1,23)}=25.67\right.$, $p<0.001)$. Post hoc tests revealed that the APV group froze less on day 36 than during their drug-free test the previous day, and less than the Veh group on day 36 ( $p<0.001)$. Thus, NMDARs in RSC are necessary for the retrieval of remotely acquired context fear memories.
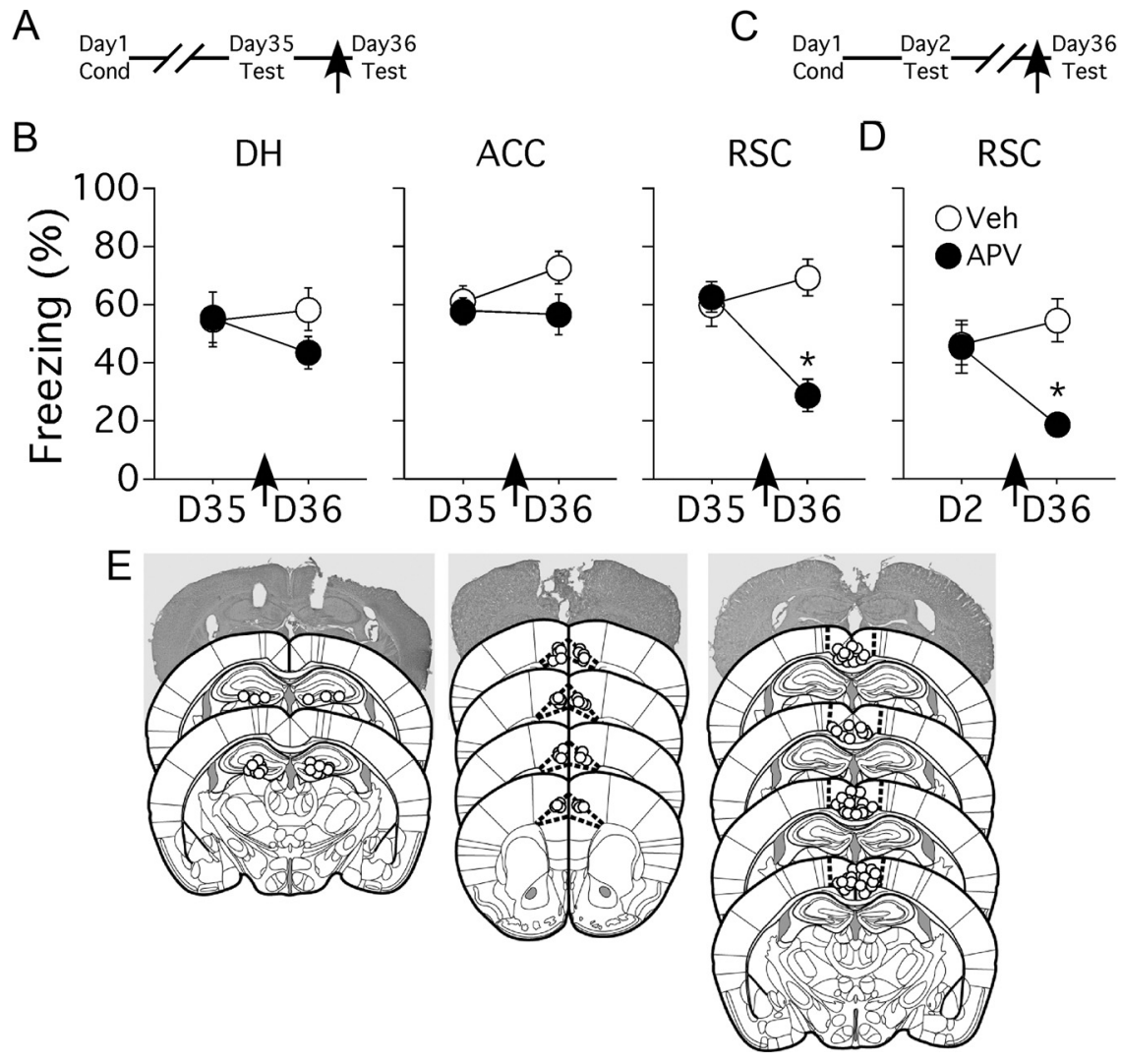

Figure 1. $\boldsymbol{A}$, Experimental design for experiments in $\boldsymbol{B}$. $\boldsymbol{B}$, NMDARs in RSC are necessary for retrieval of remote context fear memory. Infusion of APV into DH (APV: $n=8$; Veh: $n=8$; left) or ACC (APV: $n=16$; Veh: $n=18$; center) had no effect, whereas 作 6; Veh: $n=6$ ). Arrows indicate infusions. ${ }^{*} p<0.001 . \boldsymbol{E}$, Cannula placements in DH (left), ACC (center), and RSC (right). The photomicrographs show cresyl violet-stained coronal sections with representative cannula placements in each region. Illustrated below those are the locations of cannula placements in each region. Atlas templates adapted from Paxinos and Franklin (2001).

In contrast, APV infused into DH or ACC had no effect on context fear retrieval. For DH-infused mice (Fig. 1B, left), ANOVA revealed no main or interaction effects ( $F s \leq 2.25$; $p s \geq$ $0.2)$. Post hoc tests revealed no differences in freezing by the APV group from day 35 to day $36(p=0.5)$ or between APV and Veh groups on day $36(p=0.3)$. For ACC-infused mice (Fig. $1 B$, center), ANOVA revealed no main or interaction effects ( $F_{\mathrm{S}} \leq$ 2.15 ; $p s \geq 0.15)$. Post hoc tests revealed no differences in freezing by the APV group from day 35 to day $36(p=1.0)$ or between APV and Veh groups on day $36(p=0.1)$. Thus, contrary to RSC, NMDARs in DH and ACC are not necessary for the retrieval of remotely acquired context fear memories.

The drug-free test on day 35 may have initiated the formation of a new memory trace, such that even our tests performed on day 36 could have been tests for recently formed memories. To address this issue, mice were conditioned, tested on day 2 drug free, and returned for a remote memory test on day 36 after intra-RSC infusions of APV or Veh (Fig. $1 C, D)$. ANOVA revealed a significant main effect of infusion $\left(F_{(1,10)}=5.87, p=0.036\right)$ and a significant infusion by test day interaction $\left(F_{(1,10)}=6.52, p=0.029\right)$, but no main effect of test day. Post hoc tests revealed that the APV group froze significantly less than the Veh group on day $36(p<0.04)$. These data confirm that the freezing deficits observed following RSC NMDAR blockade result from a specific inability to retrieve the remotely acquired context fear memory. 
A

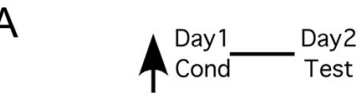

B
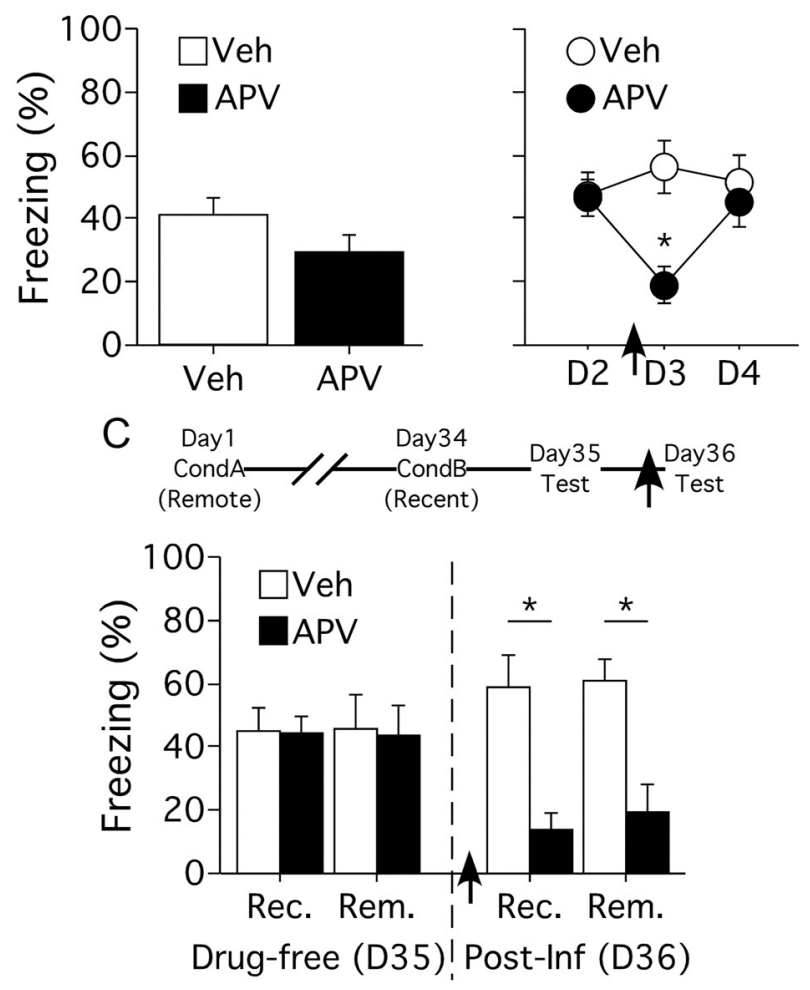

Figure 2. $\quad A$, NMDARs in RSC are not necessary for context fear learning. Mice were infused with Veh $(n=10)$ or APV $(n=17)$ before context conditioning. The following day, there was no difference in freezing levels to the conditioning context. $\boldsymbol{B}$, NMDARs in RSC are necessary for retrieval of recent context fear memory. APV infusions into RSC reduced freezing to the conditioning context on day 3 . When the mice were returned to the conditioning context drug-free (day 4), freezing levels returned to normal (APV: $n=6$; Veh: $n=6$ ). C, RSC is equally involved in recent and remote memory retrieval. In a within-subjects experiment, infusion of APV into RSC reduced freezing to contexts in which conditioning had occurred $1 \mathrm{~d}$ (Recent) and $36 \mathrm{~d}$ (Remote) prior (APV: $n=9$; Veh: $n=9$ ). Arrows indicate infusions. ${ }^{*} p<0.04$.

\section{NMDARs in RSC are necessary for retrieval of recent context} fear memories but not fear learning or storage

We next examined whether RSC NMDARs exclusively mediate the retrieval of remote memory or also contribute to fear conditioning and recent memory retrieval. To determine whether RSC NMDARs are involved in fear conditioning, APV or Veh was infused into RSC before training. During a drug-free test the following day, there was no difference in freezing levels between the two groups $\left(t_{(1,25)}=2.33 ; p=0.14\right)$ (Fig. $\left.2 A\right)$. Thus, RSC NMDARs are involved in the retrieval, but not formation, of context fear memory.

RSC has previously been shown to be necessary for retrieval of recent context fear memory (Keene and Bucci, 2008a,b). We therefore examined whether this role for RSC also depends on NMDARs. The experimental procedure is illustrated in Figure $2 \mathrm{~B}$. On day 3 , infusion of APV into RSC drastically reduced freezing to the conditioning context (Fig. $2 B$ ). ANOVA revealed a significant infusion by test day interaction $\left(F_{(2,20)}=6.49, p=\right.$ $0.007)$; all other effects were nonsignificant. Post hoc tests confirmed that the APV group froze significantly less than the Veh group only on day $3(p=0.005)$. These data demonstrate that RSC NMDARs are also necessary for the retrieval of recent context fear memory. Moreover, NMDAR blockade in RSC does not disrupt memory storage, as freezing levels returned to normal during a subsequent drug-free test.

To determine whether RSC is preferentially involved in the retrieval of recent versus remote context fear memories, we used a within-subjects design in which mice were conditioned in context A on day 1 (remote) and in context B on day 34 (recent). On day 35 , mice were tested for fear to both contexts (tests were separated by $5 \mathrm{~min}$; order of context presentation was counterbalanced) (Fig. 2C, left). On day 36, mice were infused with APV or Veh (Fig. $2 C$, right) before a second test in each context. ANOVA revealed a significant main effect of infusion $\left(F_{(1,16)}=\right.$ $18.48, p<0.001)$; all other effects were nonsignificant. Post hoc tests indicated that the APV group froze significantly less than controls during both recent and remote tests ( $p s<0.001)$. Thus, NMDARs in RSC are equally necessary for the retrieval of recently and remotely acquired context fear memories.

\section{NMDAR blockade in RSC does not affect performance of freezing behavior}

Rather than disrupting fear memory retrieval, APV could have caused hyperlocomotion or a general inability of mice to perform the freezing response. We addressed these possibilities by measuring locomotor activity, freezing to a tone CS, and postshock freezing during a multiple-shock context conditioning session. Before tone and shock presentation on day 1 , mice in the APV and Veh groups had similar locomotor activity (Fig. 3A). During testing on day $3, \mathrm{APV}$-infused mice froze significantly less than controls, replicating the results of the previous experiment (data not shown), and were significantly more active than controls $\left(t_{(1,15)}=6.38 ; p=0.02\right)$. Importantly, activity on day 3 in the APV group was not significantly different from day 1 , when they were exposed to the context drug-free before receiving any footshock $\left(t_{(1,8)}=0.15 ; p=0.71\right)$, suggesting that blockade of NMDARs in RSC did not cause hyperlocomotion.

Following this test, we examined whether NMDAR blockade in RSC prevents mice from being able to freeze. Mice were redivided into two groups matched for freezing on day 3 , and on day 4 , they received infusions of APV or Veh before testing in a novel context (context B) for fear to the tone CS (Fig. 3B). Mice in the APV group froze less during the $3 \mathrm{~min}$ pretone period $\left(t_{(1,15)}=\right.$ $2.66 ; p=0.01$ ), but there was no difference between the groups in freezing during the tone $\left(t_{(1,15)}=1.26, p=0.12\right)$. These results suggest that NMDAR blockade in RSC does not cause a general impairment in freezing behavior.

Finally, APV could have specifically impaired freezing to a context. To rule this out, we examined the effect of APV on postshock freezing. APV or Veh were infused before a single conditioning session consisting of five footshocks (Fig. 3C). Freezing was measured for $3 \mathrm{~min}$ before the first shock, during the $60 \mathrm{~s}$ intervals between shocks, and for $60 \mathrm{~s}$ after the final shock. ANOVA revealed a main effect of postshock minute, due to the progressive increase in freezing after each shock $\left(F_{(5,50)}=14.72\right.$; $p<0.001)$; all other effects were nonsignificant, indicating no difference in freezing between APV- and Veh-infused mice. Collectively, these data demonstrate that blockade of NMDARs in RSC prevents the retrieval of context fear memories without affecting motor behavior or the ability of mice to perform the freezing response.

\section{NR2A- but not NR2B-containing NMDARs or AMPARs mediate RSC-dependent context fear retrieval}

We previously demonstrated that hippocampal NR2A and NR2B subunit-containing NMDARs are differentially involved in con- 
text fear conditioning (Gao et al., 2010). We therefore used the NR2A-preferring and NR2B-selective antagonists NVP and Ro to determine the contribution of individual NR2 subtypes to retrieval of recent and remote context fear memory retrieval. We also tested the specificity of our findings for NMDA versus other glutamate receptors with the AMPAR antagonist CNQX. Infusion of NVP, but not Ro, dramatically reduced freezing during recent context fear memory testing (Fig. $4 A$, left). ANOVA revealed main effects of infusion $\left(F_{(2,20)}=5.15, p=0.02\right)$ and test day $\left(F_{(1,20)}=20.45, p<0.001\right)$, and an infusion by test day interaction $\left(F_{(2,20)}=\right.$ 33.97, $p<0.001)$. Post hoc tests revealed that only the NVP group froze less on day 3 than on day 2 , and less than the other two groups on day 3 ( $p s<0.001$ ). CNQX had no effect (Fig. 4A, right). Similarly, infusion of NVP, but not Ro, reduced freezing during remote context fear memory testing (Fig. $4 B$, left). ANOVA revealed no main effect of infusion, but a significant main effect of test day $\left(F_{(1,17)}=27.53, p<\right.$ $0.001)$ and an infusion by test day interaction $\left(F_{(2,17)}=13.29\right.$, $p<0.001)$. Post hoc tests revealed that only the NVP group froze less on day 36 than on day 35 , and less than the other two groups on day 36 ( $p s<0.01$ ). Again, CNQX had no effect (Fig. $4 B$, right). Thus, context fear memory retrieval by RSC is specifically dependent upon NR2A subunit-containing NMDARs, but not NR2B or AMPARs.

\section{Discussion}

We demonstrate that NMDARs in RSC are essential for the retrieval of both recent and remote memories. This role of RSC is particular for memory retrieval, but not consolidation or storage, and relies specifically on the activity of NR2A subunit-containing NMDARs, but not NR2B or AMPARs. This was a surprising finding, in that it lies in perfect contrast to the effects of blocking hippocampal NMDARs, which disrupts the acquisition and consolidation, but not retrieval, of context fear conditioning (Quinn et al., 2005; Matus-Amat et al., 2007), and AMPARs, which impairs retrieval (Bast et al., 2005). Different contributions of glutamate receptors may underlie the different nature of cortex-dependent versus hippocampus-dependent memory retrieval: hippocampal mechanisms yield vivid and detailed memories, whereas cortical retrieval is thought to be "fuzzier" and more generalized (Winocur et al., 2010).

RSC NMDAR antagonism could have caused a number of effects other than disrupted memory retrieval, such as impaired memory consolidation or sensory-motor function, erasure of the memory trace, or an inability to express fear responses. However, we are able to rule these possibilities out because (1) preconditioning APV infusion had no effect on freezing the following day (Fig. $2 A$ ), indicating normal sensory-motor function and memory consolidation; (2) $24 \mathrm{~h}$ after APV infusion, freezing was normal during drug-free tests (Fig. 2B), suggesting intact memory storage; and (3) APV failed to prevent freezing to a tone or during a multiple-shock conditioning session (Fig. 3B,C), ruling out a behavioral deficit. Moreover, normal freezing during a drug-free test the day after APV infusion (Fig. $2 B$ ) indicates that other memory processes, such as reconsolidation and extinction, were unaffected by RSC NMDAR blockade.

The standard model of memory storage posits that extrahippocampal sites including the neocortex are preferentially in-
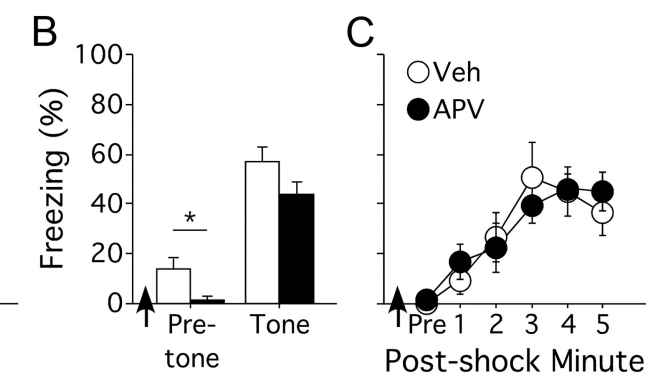

Post-shock Minute

Figure 3. NMDAR blockade in RSC does not affect locomotion, tone fear, or freezing behavior. $\boldsymbol{A}$, Infusion of APV into RSC prevented the conditioning-induced decrease in locomotion, but did not cause hyperlocomotion, as activity during testing in the 列 freezing to a tone $C S$ in a novel context (APV: $n=8 ;$ Veh: $n=9$ ). C, Infusion of APV into RSC does not block postshock freezing (APV: $n=6$; Veh: $n=6$ ). Arrows indicate infusions. * $p \leq 0.02$.
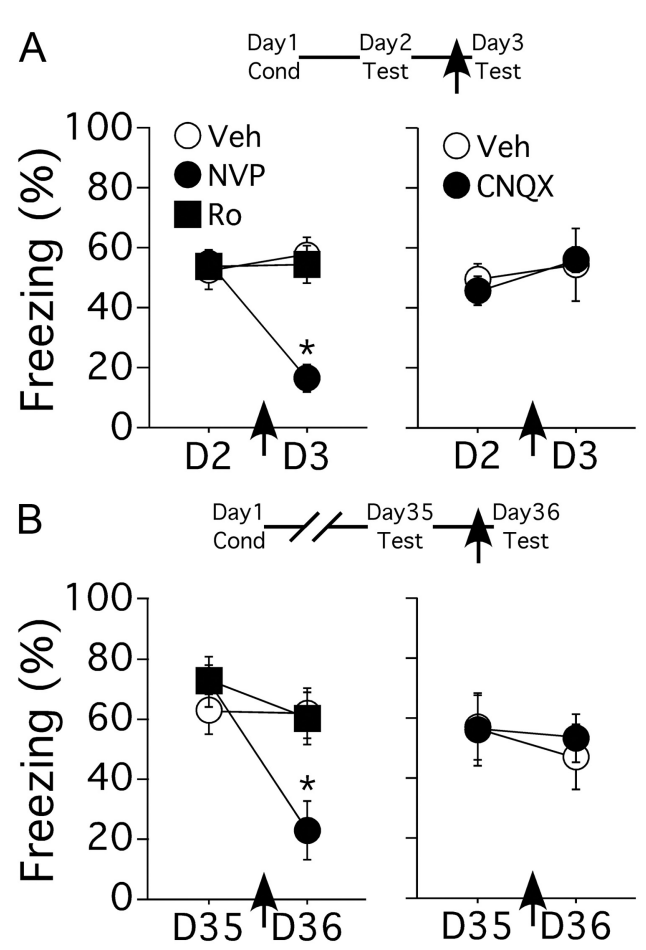

Figure 4. NR2A subunit-containing NMDARs mediate context fear memory retrieval by RSC $\boldsymbol{A}$, Retrieval of recent context fear memory was blocked by infusion of the preferential NR2A antagonist NVP, but not the specific NR2B antagonist Ro (NVP: $n=8$; Ro: $n=8$; Veh: $n=7$; left), or the AMPAR antagonist CNQX (CNQX: $n=8$; Veh: $n=7$; right). $B$, Remote fear memory retrieval was similarly disrupted by NVP, but not Ro (NVP: $n=6 ;$ Ro: $n=6$; Veh: $n=7$; left) or CNQX (CNQX: $n=7$; Veh: $n=8$; right).

volved in remote memory retrieval (Frankland and Bontempi, 2005). In support of this model, inactivation (Frankland et al., 2004) or DNA demethylation (Miller et al., 2010) of ACC and lesions of secondary sensory cortices (Sacco and Sacchetti, 2010) disrupt remote memory but leave recent memory intact. Given the predominant and expansive activation of cortical areas by remote versus recent memory retrieval (Frankland and Bontempi, 2005), one would therefore expect that focal cortical manipulations (1) would not affect the retrieval of recent memories; and (2) would be insufficient to significantly disrupt remote memory. Unexpectedly, we demonstrate that discrete, reversible antagonism of NMDARs in RSC is sufficient to disrupt context freezing during both recent and remote memory tests. Pharmacological inactivation of medial prefrontal cortex (Blum et al., 
2006; Leon et al., 2010; cf. Frankland et al., 2004) and lesions of perirhinal and postrhinal cortices (Burwell et al., 2004) produced similar effects. These cortical regions may thus serve as nodal points for time-independent memory retrieval.

Several recent studies using sodium channel blockade, which eliminates all neural activity, have identified a role for ACC in remote memory (Bontempi et al., 1999; Frankland et al., 2004), but the NMDAR blockade used in our study was ineffective. This suggests that remote memory mechanisms in ACC either use different glutamate receptors than RSC, or other neurotransmitters altogether. Interestingly, NMDARs in ACC and RSC also differ with respect to their roles in memory formation: whereas NR2B in ACC are necessary for context fear conditioning (Zhao et al., 2005), neither NR2A nor NR2B in RSC is involved.

The time-independent role for RSC in retrieval of context fear memories suggests that dysfunction in this region may contribute to the persistence of fear and anxiety that is the hallmark of PTSD. Additionally, RSC is among the first areas of the brain to show metabolic decline, in the absence of overt neuropathology, in both mild cognitive impairment and Alzheimer's disease (Minoshima et al., 1997). RSC may therefore provide a useful target for pharmacotherapeutic treatments for anxiety disorders as well as aging-related cognitive decline.

\section{References}

Aggleton JP (2010) Understanding retrosplenial amnesia: insights from animal studies. Neuropsychologia 48:2328-2338.

Anagnostaras SG, Maren S, Fanselow MS (1999) Temporally graded retrograde amnesia of contextual fear after hippocampal damage in rats: within-subjects examination. J Neurosci 19:1106-1114.

Barros DM, Izquierdo LA, Mello e Souza T, Ardenghi PG, Pereira P, Medina JH, Izquierdo I (2000) Molecular signaling pathways in the cerebral cortex are required for retrieval of one-trial avoidance learning in rats. Behav Brain Res 114:183-192.

Bast T, da Silva BM, Morris RG (2005) Distinct contributions of hippocampal NMDA and AMPA receptors to encoding and retrieval of one-trial place memory. J Neurosci 25:5845-5856.

Blum S, Hebert AE, Dash PK (2006) A role for the prefrontal cortex in recall of recent and remote memories. Neuroreport 17:341-344.

Bontempi B, Laurent-Demir C, Destrade C, Jaffard R (1999) Timedependent reorganization of brain circuitry underlying long-term memory storage. Nature 400:671-675.

Burwell RD, Bucci DJ, Sanborn MR, Jutras MJ (2004) Perirhinal and postrhinal contributions to remote memory for context. J Neurosci 24:11023-11028.

Frankland PW, Bontempi B (2005) The organization of recent and remote memories. Nat Rev Neurosci 6:119-130.

Frankland PW, Bontempi B, Talton LE, Kaczmarek L, Silva AJ (2004) The involvement of the anterior cingulate cortex in remote contextual fear memory. Science 304:881-883.

Gao C, Gill MB, Tronson NC, Guedea AL, Guzmán YF, Huh KH, Corcoran KA, Swanson GT, Radulovic J (2010) Hippocampal NMDA receptor subunits differentially regulate fear memory formation and neuronal signal propagation. Hippocampus 20:1072-1082.

Haijima A, Ichitani Y (2008) Anterograde and retrograde amnesia of place discrimination in retrosplenial cortex and hippocampal lesioned rats. Learn Mem 15:477-482.

Izquierdo I, Quillfeldt JA, Zanatta MS, Quevedo J, Schaeffer E, Schmitz PK, Medina JH (1997) Sequential role of hippocampus and amygdala, entorhinal cortex and parietal cortex in formation and retrieval of memory for inhibitory avoidance in rats. Eur J Neurosci 9:786-793.

Keene CS, Bucci DJ (2008a) Contributions of the retrosplenial and posterior parietal cortices to cue-specific and contextual fear conditioning. Behav Neurosci 122:89-97.

Keene CS, Bucci DJ (2008b) Neurotoxic lesions of retrosplenial cortex disrupt signaled and unsignaled contextual fear conditioning. Behav Neurosci 122:1070-1077.

Leon WC, Bruno MA, Allard S, Nader K, Cuello AC (2010) Engagement of the PFC in consolidation and recall of recent spatial memory. Learn Mem 17:297-305.

Matus-Amat P, Higgins EA, Sprunger D, Wright-Hardesty K, Rudy JW (2007) The role of dorsal hippocampus and basolateral amygdala NMDA receptors in the acquisition and retrieval of context and contextual fear memories. Behav Neurosci 121:721-731.

Miller CA, Gavin CF, White JA, Parrish RR, Honasoge A, Yancey CR, Rivera IM, Rubio MD, Rumbaugh G, Sweatt JD (2010) Cortical DNA methylation maintains remote memory. Nat Neurosci 13:664-666.

Minoshima S, Giordani B, Berent S, Frey KA, Foster NL, Kuhl DE (1997) Metabolic reduction in the posterior cingulated cortex in very early Alzheimer's disease. Ann Neurol 42:85-94.

Paxinos G, Franklin KBJ (2001) The mouse brain in stereotaxic coordinates. San Diego: Academic.

Piefke M, Pestinger M, Arin T, Kohl B, Kastrau F, Schnitker R, Vohn R, Weber J, Ohnhaus M, Erli HJ, Perlitz V, Paar O, Petzold ER, Flatten G (2007) The neurofunctional mechanisms of traumatic and non-traumatic memory in patients with acute PTSD following accident trauma. Neurocase 13:342-357.

Quinn JJ, Loya F, Ma QD, Fanselow MS (2005) Dorsal hippocampus NMDA receptors differentially mediate trace and contextual fear conditioning. Hippocampus 15:665-674.

Rosenbaum RS, Ziegler M, Winocur G, Grady CL, Moscovitch M (2004) "I have often walked down this street before": fMRI studies on the hippocampus and other structures during mental navigation of an old environment. Hippocampus 14:826-835.

Sacco T, Sacchetti B (2010) Role of secondary sensory cortices in emotional memory storage and retrieval in rats. Science 329:649-656.

Solomon Z, Horesh D, Ein-Dor T (2009) The longitudinal course of posttraumatic stress disorder symptom clusters among war veterans. J Clin Psychiatry 70:837-843.

Squire LR, Stark CEL, Clark RE (2004) The medial temporal lobe. Annu Rev Neurosci 27:279-306.

Steinvorth S, Corkin S, Halgren E (2006) Ecphory of autobiographical memories: an fMRI study of recent and remote memory retrieval. Neuroimage 30:285-298.

Winocur G, Moscovitch M, Bontempi B (2010) Memory formation and long-term retention in humans and animals: convergence towards a transformation account of hippocampal-neocortical interactions. Neuropsychologia 48:2339-2356.

Zhao MG, Toyoda H, Lee YS, Wu LJ, Ko SW, Zhang XH, Jia Y, Shum F, Xu H, Li BM, Kaang BK, Zhuo M (2005) Roles of NMDA NR2B subtype receptor in prefrontal long-term potentiation and contextual fear memory. Neuron 47:859-872. 